\title{
Monitoring of the Environmental Contamination and Exposure Risk of COVID-19 in the Medical Staff of Coronavirus Referral Hospitals in Qom, Iran
}

\author{
Saeed Shams ${ }^{1}$, Rahim Aali ${ }^{2}$, Mehdi. Safa ${ }^{2}$, Yadollah. Ghafuri ${ }^{2 *}$, Zahra. Atafar ${ }^{3}$ \\ ${ }^{1}$ Cellular and Molecular Research Center, Qom University of Medical Sciences, Qom, Iran \\ ${ }^{2}$ Research Center for Environmental Pollutants, Qom University of Medical Sciences, Qom, Iran \\ ${ }^{3}$ Social Development \& Health Promotion Research Center, Health Institute, Kermanshah University of Medical Sciences, Kermanshah, Iran
}

Received: $14 / 08 / 2020$

Accepted: 25/10/2020

Published: 20/03/2021

\begin{abstract}
COVID-19 is a new infection that first occurred in China and now is spreading worldwide. The disease is considered to be a serious respiratory disease in humans. This study has been designed to assess surface contamination of SARS-CoV-2and exposure risk of the disease in the medical staff of two coronavirus referral hospitals of Qom province, which were dedicated to the admission and treatment of COVID -19 patients.. This study was carried in two steps including analysis of environmental samples and exposure risk assessment of COVID-19. In this study 50 environmental samples were collected from different sites of the hospitals. After extracting RNA, RTPCR was done for the detection of SARS-CoV-2. The results showed that $18 \%$ of environmental sites, including elevator buttons (8\%), doorknobs (6\%) and bed rails (4\%) were positive. In the risk assessment process based on according to wear of personal protective equipment, exposed to high touch surfaces, performing hand hygiene, any accident with biological fluid/respiratory secretions, the results indicate that $60.4 \%, 68.3 \%, 28.6 \%$ and $20.6 \%$ health care personal including medical doctors, nurses and assistant nurses have high risk, respectively. In general, implement a plan for monitoring health personnel exposed to confirmed COVID-19 cases for respiratory illness including environmental surveillance engineering controls and personal protective equipment recommended.
\end{abstract}

Keywords: COVID-19; Environment; Risk; Exposure; Hospitals

\section{Introduction}

Coronavirus disease (COVID-19) is an infectious disease affected by a new coronavirus. The disease causes flu-like respiratory illness with different symptoms such as cough, fever, shortness of breath, and breathing difficulties, etc. $(1,2)$. In more severe cases, the disease can causes multiple organ failures and even death. This virus is the same member of the coronavirus family that caused the severe acute respiratory syndrome coronavirus (SARS-CoV) reported in China in 2003 and the Middle East Respiratory Syndrome (MERS-CoV) reported in Saudi Arabia in 2012. The initial cases of the COVID-19 have been linked to a live seafood market in Wuhan, China, December 2019 that was originated from an animal source and adapted to other variants as it crossed the species barrier to infect humans (3). Following the guidance of WHO on infection prevention and control strategies, it is important to ensure that environmental cleaning and disinfection procedures are consistently and correctly followed. Cleaning environmental surfaces with water and detergents and applying commonly used hospital-level disinfectants (such as sodium hypochlorite) are known as effective and sufficient procedures. Medical devices, equipment, laundries, food service utensils, and medical wastes should be managed in accordance with safe routine procedures $(4,5)$. This study was designed to assess the extent and persistence of surface contamination of COVID-19 and exposure risk of the disease in the medical staff of coronavirus admission hospitals in Qom province.

\section{Material and Methods \\ 2.1 Study setting}

The study was planned in Qom, as the first city that identified the disease in in the central part of Iran, with about 1.3 million residents, Two coronavirus referral hospitals of Qom, Kamkar and Forghani hospitals, which dedicated to the admission and treatment of COVID -19 patients, were included in this study. Their location is showed in Figure 1.

\subsection{Collection of environmental samples}

Fifty environmental samples including Ambulance patient carrier, Corridor and patient entrance, Admission and Waiting room, Patient room...were collected using sterile swabs with synthetic tips and plastic shafts. Each swab was placed into a tube containing $2 \mathrm{ml}$ of the viral transport medium (VTM) that was labeled and and putted in a self-sealing bag. Then, the outside of the sealed bag was disinfected by $5 \%$ hypochlorite solution. In each sampling round a set of control samples also were collected. The first set of control samples were handled in the same way as the environmental samples from the potentially contaminated area, including opening the package

Corresponding author: Yadollah. Ghafuri, Research Center for Environmental Pollutants, Qom University of Medical Sciences, Qom, Iran. Tel: +98 2532852740 E-mail: yadollahghafuri@yahoo.com 
and removing the swab from the tube, but without sampling any surfaces. The second set of control samples remains sealed, but was shipped, stored and tested with the surface samples, to exclude contamination later on. Next, the collected samples were immediately transferred to a clinical virology laboratory. For each sample collected a questionnaire including site, sampling location, ambient temperature, humidity, the situation of disinfection including disinfectant, and the last time disinfected before sampling were completed. In Table 1, sampling sites have been described based on location in selected hospitals (6).

\subsection{Detection of SARS-Cov-2}

Viral RNA extraction was done by a commercial kit (SinaClon, Iran) according to the manufacturer's protocol. cDNA was synthetized by a mix of template RNA (10 $\mu \mathrm{l})$, RT enzyme $(1 \mu \mathrm{l})$, oligo $(\mathrm{dT})(1 \mu \mathrm{l})$, and distilled water $(4 \mu \mathrm{l})$ at $42^{\circ} \mathrm{C}$ (40 min) and $85^{\circ} \mathrm{C}$ (5 min) using using cDNA synthesis kit (BioFact, South Korea).Briefly, For RT- Polymerase chain reaction (Reverse Transcription-PCR) ,two sets of primers (designed in this study), Forward (5' GTTTCGGAAGAGACAGGTAC-3) and Reversed (5'AGAATTCAGATTTTTAACACGAGAG-3) were used to amplify a fragment of $189 \mathrm{bp}$ regarding the $\mathrm{E}$ gene. The total volume of the reaction mixture was $25 \mu$ l contained $12.5 \mu \mathrm{l}$ of 2x Master Mix (Ampliqon, Denmark), $1 \mu$ of each primer (10
$\mathrm{pM}), 5.5 \mu \mathrm{l}$ distilled water, and $5 \mu \mathrm{l}$ of cDNA. The RT-PCR program was included initial denaturation at $94{ }^{\circ} \mathrm{C}$ for $4 \min (1$ cycle), followed by 40 cycles of denaturation at $94{ }^{\circ} \mathrm{C}$ for $35 \mathrm{~s}$, annealing at $55^{\circ} \mathrm{C}$ for $35 \mathrm{~s}$, and extension at $72{ }^{\circ} \mathrm{C}$ for $35 \mathrm{~s}$. Final extension was carried out at $72{ }^{\circ} \mathrm{C}$ for $5 \mathrm{~min}(1$ cycle). PCR products were analyzed by electrophoresis on agarose gel stained with DNA safe dye.

\subsection{Exposure risk assessment of COVID-19}

In order to assessment of risk, WHO guidance was used $(9,10)$ In each hospital,33 medical staff including doctor, nurse, and assistant nurse , who had the highest level of contact with patients, were selected and then interviewed with questions about exposure with COVID -19. A simplified risk exposure category based on most common scenarios with a focus on infection prevention and source control measures including use-wear of personal protective equipment (PPE) by health care personal and degree of close contact with the COVID-19 patients were considered. According to this, the criteria of exposure risk assessment of COVID-19 for health workers were direct defined care and/or close contact (at a distance of one meter) with confirmed COVID-19 patients, and any aerosol-generating procedures performed on them $(9,11)$. The risk categorization of health workers exposed to the COVID-19 is described in Table 2.
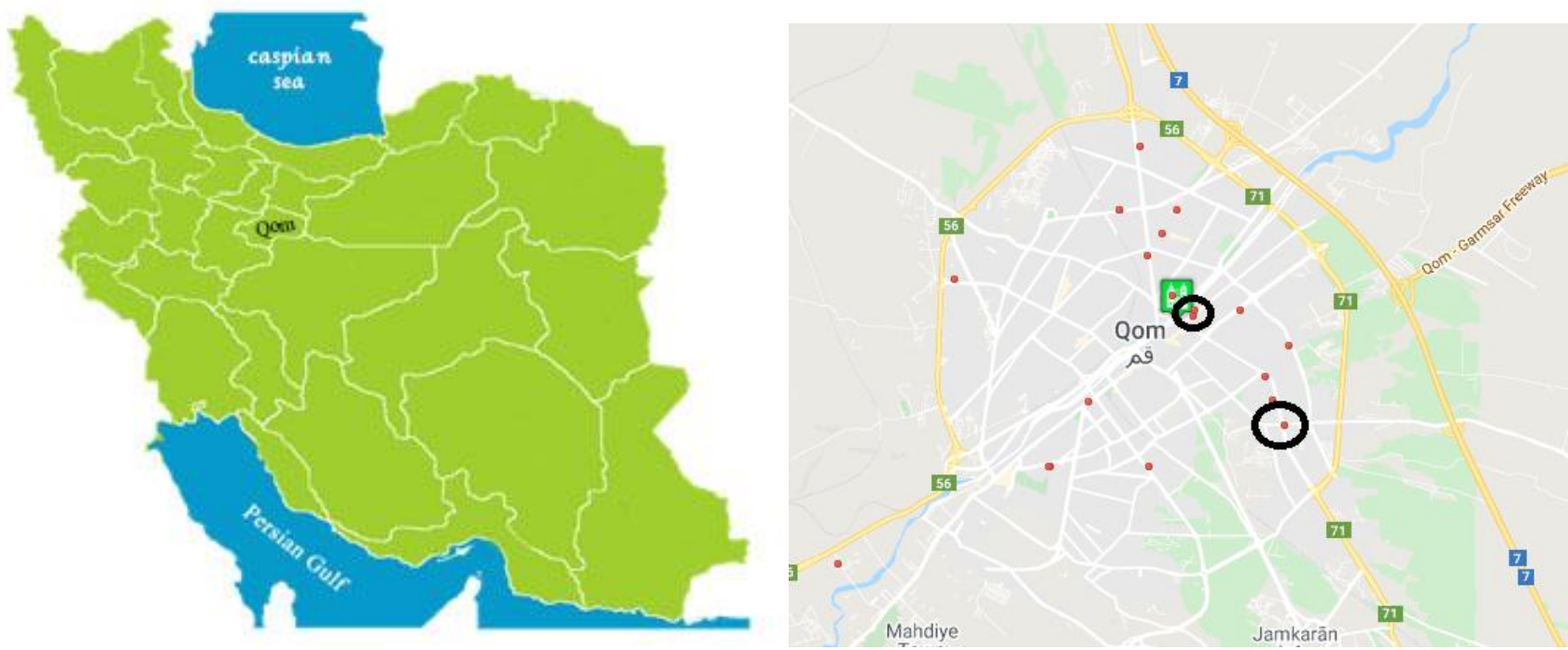

Figure 1: Location of studied area

Table 1: Sampling sites based on location in hospitals selected

\begin{tabular}{lll}
\hline Sampling locations & Sampling sites & Number of sample collected \\
\hline Ambulance patient carrier & Medical bag handle & 2 \\
& Blood pressure cuff & 2 \\
\multirow{3}{*}{ Corridor and patient entrance } & Stretcher & 2 \\
& Doorknob & 4 \\
& Light switch & 4 \\
Admission and Waiting room & Sink & 2 \\
Staff room & Doorknob & 6 \\
& Doorknob & 6 \\
Patient room & Key board & 2 \\
& Clothes & 3 \\
Patient handling & Doorknob, & 3 \\
\hline
\end{tabular}


Table 2: Risk categorization of health workers exposed to COVID-19

\begin{tabular}{|c|c|c|}
\hline $\begin{array}{l}\text { Risk } \\
\text { categorization }\end{array}$ & Defined criteria & Questions \\
\hline \multirow[t]{2}{*}{ High risk } & $\begin{array}{l}\text { The health worker did not } \\
\text { respond "Always, as } \\
\text { recommended" to } \\
\text { Questions:'Always, as } \\
\text { recommended' should be } \\
\text { considered wearing the PPE } \\
\text { when indicated more than } \\
\text { 95\% of the time; }\end{array}$ & $\begin{array}{l}\text {-During the period of a health care interaction with a COVID-19 patient, did } \\
\text { the health worker wear PPE including single gloves, medical mask, face } \\
\text { shield or goggles/protective glasses, and disposable gown? } \\
\text {-During the period of health care interaction with the COVID-19 case, were } \\
\text { high touch surfaces decontaminated frequently (at least three times daily)? }\end{array}$ \\
\hline & $\begin{array}{l}\text { The health worker responded } \\
\text { "Yes" }\end{array}$ & $\begin{array}{l}\text { During the period of a health care interaction with a COVID-19 infected } \\
\text { patient, did the health worker have any episode of accident with biological } \\
\text { fluid/respiratory secretions? }\end{array}$ \\
\hline Low risk & $\begin{array}{l}\text { The health worker responded } \\
\text { "Most of the time, } \\
\text { Occasionally, Rarely" } \\
\text { 'Most of the time' should be } \\
\text { considered } 50 \% \text { or more but } \\
\text { not } 100 \% \text {; 'occasionally' } \\
\text { should be considered } 20 \% \text { to } \\
\text { under } 50 \% \text { and 'Rarely' } \\
\text { should be considered less } \\
\text { than } 20 \% \text {. }\end{array}$ & $\begin{array}{l}\text { - During the period of a health care interaction with a COVID-19 patient, } \\
\text { did the health worker wear personal protective equipment (PPE) including } \\
\text { single gloves, medical mask, face shield or goggles/protective glasses, and } \\
\text { disposable gown? } \\
\text { - Did the health worker remove and replace your PPE according to protocol } \\
\text { (e.g. when medical mask became wet, disposed the wet PPE in the waste } \\
\text { bin, performed hand hygiene, etc)? } \\
\text { - During the period of health care interaction with the COVID-19 case, did } \\
\text { the health worker perform hand hygiene before and after touching the } \\
\text { COVID-19 patient? } \\
\text { NB: Irrespective of wearing glove } \\
\text { - During the period of health care interaction with the COVID-19 case, did } \\
\text { the health worker perform hand hygiene after touching the COVID-19 } \\
\text { patient's surroundings } \\
\text { (bed, door handle, etc)? } \\
\text { - During aerosol generating procedures on the } \\
\text { COVID-19 patient, did health worker remove and replace your PPE } \\
\text { according to protocol. } \\
\text { - During aerosol generating procedures on the } \\
\text { COVID-19 case, did you perform hand hygiene } \\
\text { before and after touching the COVID-19 patient, after touching the COVID- } \\
19 \text { patient's surroundings (bed, door handle, etc)? }\end{array}$ \\
\hline
\end{tabular}

\section{Results}

Eighteen percent of evaluated samples by RT-PCR assay, including 3 doorknob sites (6\%), 4 elevator button sites (8\%), and 2 bed rail (4\%) were positive for SARS-CoV-2. In figure 2 , gel electrophoresis is showed.

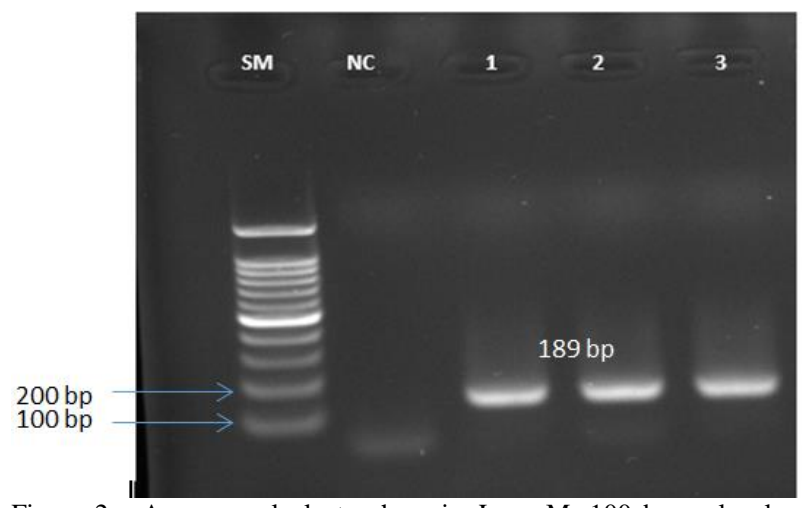

Figure 2: Agarose gel electrophoresis. Lane M, 100 bp molecular weight marker; lane NC, negative control; lanes 1-3, positive samples

In Table 3, the features of positive sites in hospital selected is presented. The effect of three types of disinfectants on SARS-CoV-2and the risk assessment and potential exposure of health care personal with COVID -19 according to risk of close contact with patients are summarized in the Tables 4and 5, respectively.

\section{Discussion}

The results of our study showed that $18 \%$ of samples evaluated by RT-PCR assay were positive for SARS-CoV-2 , including 3 doorknob sites (6\%), 4 elevator button sites $(8 \%)$ and 2 bed rails (4\%). Other samples including clothes of staff, keyboard, and stretchers of the ambulance, patient carriers, patient room, and light switch were negative, resulting in current decontamination measures were sufficient. It seems that one of the reasons for contamination in some surfaces can be related to the high load of visits and contact with these in comparison with others. In this study, according to the diagnostic method used, no information was obtained about the viability and number of virus on the surfaces. In the study of Kampf et al. on the persistence of coronaviruses on inanimate surfaces and their inactivation with biocidal agents, their results indicated that coronaviruses $(\mathrm{HCoV})$ could persist on different inanimate surfaces like metal, glass or plastic for up to 9 days, but could efficiently inactivate by surface disinfection procedures such as $71 \%$ ethanol, $0.5 \%$ hydrogen peroxide or $0.1 \%$ sodium hypochlorite within one minute (12). 
Table 3: Features of positive sites in health care settings

\begin{tabular}{|l|l|l|l|l|l|l|}
\hline $\begin{array}{l}\text { Positive } \\
\text { sampling in } \\
\text { two hospitals }\end{array}$ & $\begin{array}{l}\text { Number of } \\
\text { samples }\end{array}$ & $\begin{array}{l}\text { The last time } \\
\text { disinfected } \\
\text { sampling (h) }\end{array}$ & $\begin{array}{l}\text { Defore } \\
(\%)\end{array}$ & $\begin{array}{l}\text { Temperature } \\
\left({ }^{\circ} \mathrm{C}\right)\end{array}$ & $\begin{array}{l}\text { Humidity } \\
(\%)\end{array}$ \\
\hline Doorknob & 3 & 6 & Sodium hypochlorite & 0.2 & 21 & 23 \\
\hline $\begin{array}{l}\text { Elevator } \\
\text { Button }\end{array}$ & 4 & 5 & Sodium hypochlorite & 0.2 & 21 & 23 \\
\hline Bed rails & 2 & 10 & Sodium hypochlorite & 0.2 & 21 & 23 \\
\hline
\end{tabular}

Table 4: Effectiveness of three types of disinfectants on SARS-CoV-2

\begin{tabular}{|l|l|l|l|l|l|}
\hline Disinfectant & $\begin{array}{l}\text { Concentration } \\
(\%)\end{array}$ & $\begin{array}{l}\text { Number of total } \\
\text { sample }\end{array}$ & $\begin{array}{l}\text { Positive sample } \\
\text { after disinfection }\end{array}$ & $\begin{array}{l}\text { Exposure time } \\
(\mathrm{min})\end{array}$ & $\begin{array}{l}\text { Temperature } \\
\left({ }^{\circ} \mathrm{C}\right)\end{array}$ \\
\hline Sodium hypochlorite & 0.2 & 16 & - & 5 & 20 \\
\hline Hydrogen peroxide & 0.5 & 14 & - & 10 & 22 \\
\hline Peracetic acid & 0.25 & 10 & - & 10 & 23 \\
\hline
\end{tabular}

Table 5: Risk assessment and potential exposure of health care personal

\begin{tabular}{|c|c|c|c|c|c|c|c|c|c|}
\hline \multirow[t]{2}{*}{ Personal } & \multirow{2}{*}{$\begin{array}{l}\text { Number } \\
\text { of case } \\
\text { Evaluated } \\
\text { in two } \\
\text { hospitals }\end{array}$} & \multicolumn{2}{|c|}{ wear of PPE } & \multicolumn{2}{|c|}{$\begin{array}{l}\text { exposed to high touch } \\
\text { surfaces }\end{array}$} & \multicolumn{2}{|c|}{$\begin{array}{l}\text { performing hand } \\
\text { hygiene }\end{array}$} & \multicolumn{2}{|c|}{$\begin{array}{l}\text { any accident with } \\
\text { biological } \\
\text { fluid/respiratory } \\
\text { secretions }\end{array}$} \\
\hline & & $\begin{array}{l}\text { High-risk } \\
(\%)\end{array}$ & $\begin{array}{l}\text { Low- } \\
\text { risk } \\
(\%)\end{array}$ & $\begin{array}{l}\text { High-risk } \\
(\%)\end{array}$ & $\begin{array}{l}\text { Low- } \\
\text { risk } \\
(\%)\end{array}$ & $\begin{array}{l}\text { High-risk } \\
(\%)\end{array}$ & $\begin{array}{l}\text { Low- } \\
\text { risk } \\
(\%)\end{array}$ & $\begin{array}{l}\text { High-risk } \\
(\%)\end{array}$ & $\begin{array}{l}\text { Low-risk } \\
(\%)\end{array}$ \\
\hline Doctor & 14 & 14.2 & 57.1 & 14.2 & 42.8 & - & 14.2 & - & 7.1 \\
\hline Nurse & 31 & 12.9 & 48.3 & 16.1 & 11 & 9.6 & 5 & 6.4 & 3.2 \\
\hline Assistant nurse & 21 & 33.3 & 57.1 & 38 & 18 & 19 & 7 & 14.2 & 9.5 \\
\hline
\end{tabular}

So, it is consistent with the results of the present study. Study of Jiang et al. about hospital environmental hygiene monitoring by quantitative real-time PCR methods, showed that viruses could be detected on the surfaces of the nurse station in the isolation areas with suspected patients and also in the air of the isolation ward with an intensive care patients (13, 15).The results of the effectiveness of the three disinfectant compounds including sodium $0.2 \%$, hypochlorite $0.2 \%$ hydrogen peroxide and $0.25 \%$ Peracetic acid is presented in Table 3. Due to the negative results of all samples after disinfection for three compounds of disinfectant, it has the same effectiveness in the concentrations used which is similar to the results of other available studies and reports $(13,14)$. Risk assessment and potential exposure of health care personal with COVID -19 according to wear of PPE, exposed to high touch surfaces, performing hand hygiene, any accident with biological fluid/respiratory secretions, the results indicated $60.4 \%, 68.3 \%, 28.6 \%$, and $20.6 \%$ health care personal including doctors, nurses and assistant nurses,respectively. However, the results are different for assessing the risk of exposure to the patient's equipped personal protection (control at source) and include $12.8 \%$ and $15.1 \%$ for high and medium risk, respectively. Other studies have been documented increased transmission risk associated with COVID -19 among health care personnel. Heinzerling et al. evaluated health care personnel who were tested for SARS-CoV-2 and participated in interviews, according to PPE use and exposure characteristics and assessed for transmission of COVID-19, their findings indicated that $77 \%$ of personnel having high and medium risk $(10,11)$. Risk exposure to COVID-19 in pregnant healthcare workers reported by Belingheri et al. They showed that pregnant worker should not be exposed to confirmed or suspected COVID-19 patients, even if they wear appropriate personal protective equipment (16). This result is compatible with the present study. In order to respond and control the transmission and expansion of COVID-19 according to WHO protocols attention, environmental factors and hazards are inevitable $(17,18)$.

\section{Conclusion}

Our report is one of the first to demonstrate the contamination of the hospital surfaces with SARS-CoV-2. Our findings also emphasize the concern of the exposure risk of the personnel of hospitals with COVID-19. Therefore, a regular program should be adopted to monitor the disinfection of surfaces and the proper use of personal protective equipment in high-risk health personnel, as well as environmental controls and hospital equipment.

\section{Acknowledgments}

We thank the staff of Kamkar and Forghani Hospitals of Qom University of Medical Sciences.

\section{Ethical issue}

Authors are aware of, and comply with, best practice in publication ethics specifically with regard to authorship (avoidance of guest authorship), dual submission, manipulation of figures, competing interests and compliance with policies on research ethics. Authors adhere to publication requirements that submitted work is original and has not been published elsewhere in any language.

\section{Competing interests}

The authors declare that there is no conflict of interest that would prejudice the impartiality of this scientific work.

\section{Authors' contribution}

All authors of this study have a complete contribution for data collection, data analyses and manuscript writing. 


\section{Funding}

"Not applicable"

\section{Ethics approval and consent to participate}

This study was supported by Qom University of Medical Sciences by ethic number (IR.MUQ.REC.1398.162). All dataset analyzed during the current study is publicly available at the Qom University of Medical Sciences.

\section{References}

1. Ahmed Al-Mandhari, Dalia Samhouri,Abdinasir Abubakar, Richard Brennan, Coronavirus Disease 2019 outbreak: preparedness and readiness of countries in the Eastern Mediterranean Region, EMHJ - Vol. 26 No. 2 - 2020

2. Jieliang Chen, Pathogenicity and transmissibility of 2019-nCoVdA quick overviewand comparison with other emerging viruses, Microbes and Infection, 2020.

3. Waleed Alhazzani, Morten Hylander Møller, Yaseen M. Arabi, Mark Loeb, Michelle Ng Gong6, Eddy Fan,Simon Oczkowski, Mitchell M. Levy, Lennie Derde, Surviving Sepsis Campaign: guidelinesOn the management of critically ill adults with Coronavirus Disease 2019 (COVID-19), 2020, Intensive Care Med https://doi.org/10.1007/s00134-020-06022-5.

4. WHO, Responding to community spread of COVID-19 Interim guidance 7 March 2020.

5. WHO, Infection prevention and control during health care when novel coronavirus ( $\mathrm{nCoV}$ ) infection is suspected Interim guidance 25 January 2020

6. WHO. Surface sampling of coronavirus disease (COVID-19): A practical "how to" protocol for health care and public health Professionals, 2020, EarlyInvestigations-2019-nCoV@who.int.

7. V.M. Corman, O. Landt, M. Kaiser, R. Molenkamp, A. Meijer, D.K. Chu, T. Bleicker, S. Brünink, J. Schneider, M.L. Schmidt, Detection of 2019 novel coronavirus (2019-nCoV) by real-time RT-PCR, Eurosurveillance 25(3) (2020).

8. Wang W, Xu Y, Gao R, Lu R, Han K, Wu G, et al. Detection of SARS-CoV-2 in Different Types of Clinical Specimens. JAMA. 2020 .

9. WHO, Health workers exposure risk assessment and management in the context of COVID-19 virus, Interim guidance 4 March 2020

10. Rachel M. Burke, Claire M. Midgley, Alissa Dratch , Marty Fenstersheib, Active Monitoring of Persons Exposed to Patients with Confirmed COVID-19 - United States, January-February 2020, MMWR / March 6, 2020 / Vol. 69 / No. 9.

11. Amy Heinzerling, Matthew J. Stuckey, Tara Scheuer, Kerui Xu, Kiran M. Perkins, Heather Resseger, Shelley Magill, Jennifer R. Verani, Seema Jain, Meileen Acosta,Erin Epson, Transmission of COVID-19 to Health Care Personnel During Exposures to a Hospitalized Patient - Solano County, California, February 2020, MMWR , April 17, 2020 / 69(15);472-476

12. G. Kampf , D. Todt, S. Pfaender, E. Steinmann, Persistence of coronaviruses on inanimate surfaces and their inactivation with biocidal agents,2020, Journal of Hospital Infection.

13. Yanfang Jiang, Haifeng Wang, Likun Chen, Jiaxue He,Liguo Chen, Yong Liu, Xinyuan Hu1, Ang Li1, Siwen Liu, Peng Zhang, Hongyan Zou Shucheng Hua, Clinical Data on Hospital Environmental Hygiene Monitoring and Medical Staffs Protection during the Coronavirus Disease 2019 Outbreak, medRxiv preprint doi: https://doi.org/10.1101/2020.02.25.20028043.

14. van Doremalen N, Bushmaker T, Morris DH, Holbrook MG, Gamble A, Williamson BN, et al. Aerosol and Surface Stability of SARS-CoV-2 as Compared with SARS-CoV-1. New England Journal of Medicine. 2020.

15. SWX Ong, YK Tan, PY Chia, TH Lee, OT N, Air, Surface Environmental, and Personal Protective Equipment Contamination by Severe Acute Respiratory Syndrome Coronavirus 2 (SARSCoV-2) From a Symptomatic Patient, JAMA published online March 4, 2020

16. Michael Belingheri, Maria Emilia Paladino, Michele Augusto Riva, Risk exposure to COVID-19 in pregnant healthcare workers, Journal of Occupational and Environmental Medicine, Publish Ahead of Print,DOI: 10.1097/JOM.0000000000001881.
17. Minimum requirements for infection prevention and control Geneva: World Health Organization; 2019. (Available at: https://www.who.int/infection-prevention/publications/min-reqIPC-manual/en/, accessed 20 January 2020

18. WHO guidelines on hand hygiene in health care: first global patient safety challenge - clean care is safer care. Geneva: World Health Organization; 2009 (https://apps.who.int/iris/handle/10665/44102, accessed 17 January 2020) 